and that over time, the indirect associated portion of costs remains almost constant, showing that over time the costs of indirectly related issues are becoming a larger proportion of total costs. Methodological advancements in costing attribution over time could contribute to understanding the patterns in health care resource usage among populations with chronic diseases.

Disclosure of Interests: Mark Tatangelo: None declared, George Tomlinson: None declared, J Michael Paterson: None declared, Nick Bansback: None declared, Edward Keystone Grant/research support from: AbbVie; Amgen; Gilead Sciences, Inc; Lilly Pharmaceuticals; Merck; Pfizer Pharmaceuticals; PuraPharm; Sanofi, Consultant of: AbbVie; Amgen; AstraZeneca Pharma; Bristol-Myers Squibb Company; Celltrion; F. Hoffman-La Roche Ltd.; Genentech, Inc; Gilead Sciences, Inc.; Janssen, Inc; Lilly Pharmaceuticals; Merck; Myriad Autoimmune; Pfizer Pharmaceuticals, Sandoz, Sanofi-Genzyme, Samsung Bioepsis., Speakers bureau: AbbVie; Amgen; Bristol-Myers Squibb; Celltrion; F. Hoffman-La Roche Ltd, Janssen, Inc; Merck; Pfizer Pharmaceuticals; Sanofi-Genzyme; UCB, Claire Bombardier Grant/research support from: Dr Bombardier reports sources of funding for Ontario Best Practice Research Initiative Research grants from Abbvie, Janssen, Amgen, Medexus, Merck, Pfizer, and Novartis outside of the submitted work. Consulting Agreements: Abbvie, Covance, Janssen, Merck, Pfizer, Sanofi and Novartis outside of the submitted work. Advisory Board Membership: Hospira, Sandoz, Merck, Pfizer and Novartis outside of the submitted work.

DOI: 10.1136/annrheumdis-2020-eular.126

\section{THU0546 HEALTHCARE COSTS OF NOT ACHIEVING REMISSION IN PATIENTS WITH RHEUMATOID ARTHRITIS}

M. Bergman ${ }^{1}$, L. Zhou' ${ }^{2}$, P. Patel ${ }^{2}$, R. Sawant ${ }^{2}$, J. Clewell ${ }^{2}$, N. Tundia ${ }^{2} .{ }^{1}$ Drexel University College of Medicine, Philadelphia, United States of America; ${ }_{2}^{2}$ AbbVie Inc., North Chicago, United States of America

Background: Guidelines recommend sustained remission as a treatment goal for patients with rheumatoid arthritis (RA). However, only one-third of patients are known to achieve this goal with current treatments. A few studies have evaluated the impact of remission in a real-world setting, but evidence is limited to the elderly population.

Objectives: To understand the impact of remission on healthcare costs by comparing overall and RA-related direct healthcare costs and resource use in patients with RA who maintain vs those who do not maintain remission using a real-world database.

Methods: Data for this retrospective cohort study were derived from Optum electronic health records linked to claims from commercial and Medicare Advantage health plans in the United States. Patients with $\geq 2$ diagnoses for RA, $\geq 1$ Disease Activity Score 28 (DAS28-CRP/ESR) or Routine Assessment of Patient Index Data 3 (RAPID3) measurement, and continuous medical and pharmacy coverage 6 months before and 1 year after the index date were included. Two cohorts were created: remission and non-remission. Remission was defined as DAS2 $<2.6$ or RAPID3 $\leq 3.0$. In the remission cohort, the index date was defined as the first date remission was achieved. In the non-remission cohort, the index date was defined as the first date of DAS28 or RAPID3 measurement. Outcomes were all-cause and RA-related total, medical, and prescription costs; healthcare resource use (number of inpatient, emergency department [ED], outpatient, and other visits); and number of prescriptions within 1 year of index date. A weighted generalized linear model and binomial regression were used to estimate adjusted annual direct costs and healthcare resource use, respectively. Confounding between cohorts due to age, sex, race and comorbidities using the Elixhauser index was controlled for in the models.

Results: A total of 335 patients with RA (remission cohort: 125; non-remission cohort: 210) met the study inclusion criteria. Annual all-cause total direct costs in the remission cohort were significantly less than in the non-remission cohort $(\$ 30,427$ vs $\$ 38,645$, respectively; cost ratio $(\mathrm{CR})=0.79 ; 95 \% \mathrm{Cl}: 0.63,0.99)$. All-cause medical costs were significantly lower in the remission cohort than in the non-remission cohort (Figure 1); furthermore, among all-cause medical costs, outpatient visit costs were significantly lower in the remission than in the non-remission cohort. All-cause resource use (mean number of visits) was less in the remission vs non-remission cohort: inpatient $(0.23$ vs 0.63 ; visit ratio $(\mathrm{VR})=0.36 ; 95 \% \mathrm{Cl}: 0.19,0.70)$, $\mathrm{ED}(0.36$ vs $0.77 ; \mathrm{VR}=0.47 ; 95 \% \mathrm{Cl}: 0.30$, 0.74 ), and outpatient visits ( 20.7 vs $28.5 ; \mathrm{VR}=0.73 ; 95 \% \mathrm{Cl}: 0.62,0.86$ ). Annual RA-related total direct costs were similar in both cohorts (Figure 2); however, RA-related medical costs were numerically lower in the remission vs non-remission cohort $(\$ 8,594$ vs $\$ 10,002$, respectively; $C R=0.86 ; 95 \% \mathrm{Cl}: 0.59,1.25)$. RA-related resource use (mean number of visits) was less in the remission vs non-remission cohort: inpatient ( 0.15 vs 0.22 ; VR=0.67; $95 \% \mathrm{Cl}: 0.35,1.30)$, ED (0.04 vs $0.13 ; \mathrm{VR}=0.31 ; 95 \% \mathrm{Cl}: 0.10,0.95)$, and outpatient visits (5.4 vs 7.4 ; $\mathrm{VR}=0.72 ; 95 \% \mathrm{Cl}: 0.58,0.91)$
Conclusion: Significant economic burden was associated with patients who did not maintain remission compared with those who maintained remission. Although outpatient visits were the driver of medical costs in both groups studied in this analysis, the contribution of outpatient visits was greater among those who did not maintain remission.
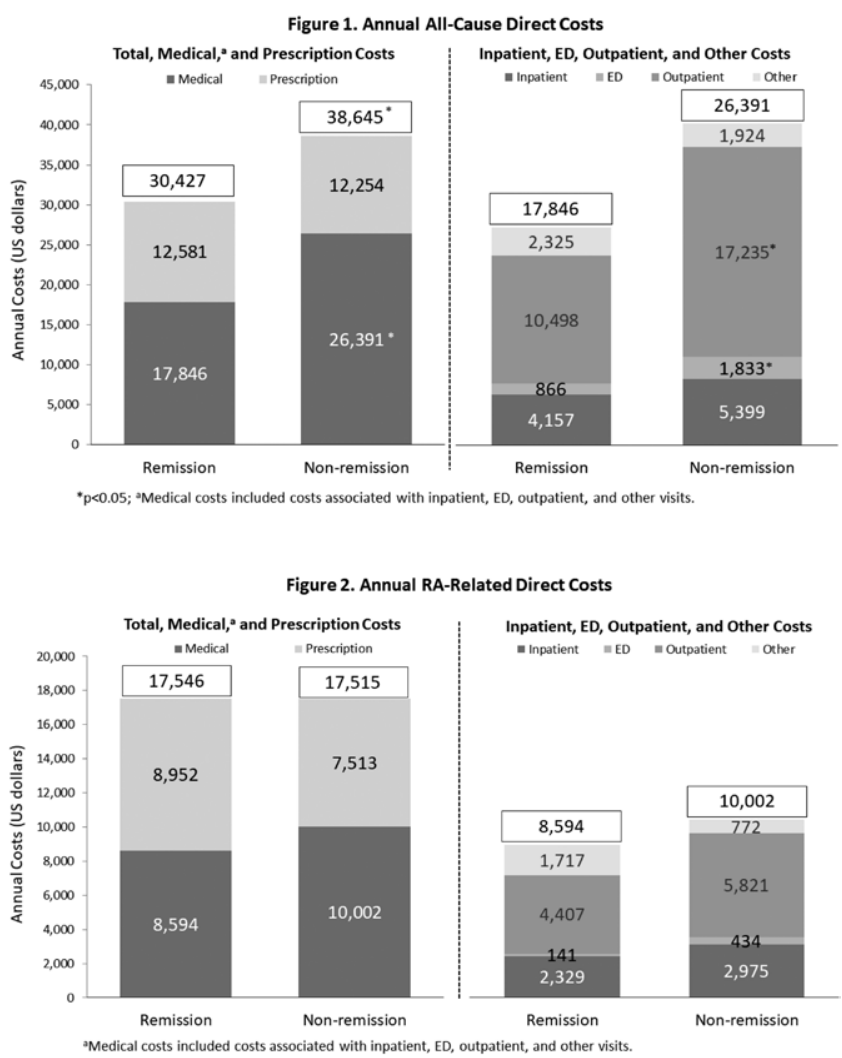

Acknowledgments: Financial support for the study was provided by AbbVie AbbVie participated in the interpretation of data, review, and approval of the abstract. All authors contributed to the development of the publication and maintained control over the final content. Medical writing services were provided by Joann Hettasch of JK Associates Inc., a member of the Fishawack Group of Companies, and funded by AbbVie.

Disclosure of Interests: Martin Bergman Shareholder of: Johnson \& Johnson - stockholder, Consultant of: AbbVie, BMS, Celgene Corporation, Genentech, Janssen, Merck, Novartis, Pfizer, Sanofi - consultant, Speakers bureau: AbbVie, Celgene Corporation, Novartis, Pfizer, Sanofi - speakers bureau, Lili Zhou Shareholder of: AbbVie, Employee of: AbbVie, Pankaj Patel Shareholder of: AbbVie, Employee of: AbbVie, Ruta Sawant Shareholder of: AbbVie, Employee of: AbbVie, Jerry Clewell Shareholder of: AbbVie, Employee of: AbbVie, Namita Tundia Shareholder of: AbbVie, Employee of: AbbVie DOI: 10.1136/annrheumdis-2020-eular.955

\section{THU0547 ESTIMATION OF THE IMPACT OF A STRATEGY TO OPTIMIZE COSTS ON NATIONAL HEALTH-CARE SYSTEM IN PATIENTS WITH RHEUMATOID ARTHRITIS: A DIRECT COST ANALYSIS}

D. F. Aranda ${ }^{1}$, T. Benincasa ${ }^{2}$, C. Romero-Sánchez ${ }^{3}$, L. Chila ${ }^{3}$, W. BautistaMolano ${ }^{3} .{ }^{1}$ National Open and Distance University, 110111, Colombia;

${ }^{2}$ Univerisdad EL Bosque, Faculty of Sciences, Department of Mathematics, 110111, Colombia; ${ }^{3}$ Universidad El Bosque, School of Dentistry, Cellular and Immunology Group / Universidad Militar Nueva Granada, School of Medicine, Hospital Militar Central-Clinical Immunology Group, 110111, Colombia

Background: Rheumatoid arthritis (RA) is a disease associated with a high and increasing direct cost to the health-care resources. It is estimated that about 250,000 persons may have RA in Colombia. The characteristic joint damage and disability associated to RA increase slowly over many years (10-20 years).

Objectives: To assess the development of RA in Colombian-population over the next five-years and to estimate the impact of a strategy to reduce direct-costs on the national health-care system 